Vol. 23, No. 1, pp. 101 109, 2020.

\title{
Phase Transition Behaviors of Lead-Free Piezoelectric $\left(\mathrm{Na}_{1 / 2} \mathrm{Bi}_{1 / 2} \mathrm{TiO}_{3}\right)_{(1-\mathrm{x})}-\left(\mathrm{BaTiO}_{3}\right)_{\mathrm{x}}$
}

\author{
Byoungwan Lee ${ }^{1}$, Haosu Luo ${ }^{2}$, Jung Kyu Kim ${ }^{1 \dagger}$
}

${ }^{1}$ School of Chemical Engineering, Sungkyunkwan University, Suwon 16419, Korea

${ }^{2}$ Shanghai Institute of Ceramics, Chinese Academy of Sciences, Shanghai 200031, China

\section{납이 포함되지 않은 압전 특성의 $\left(\mathrm{Na}_{1 / 2} \mathrm{Bi}_{1 / 2} \mathrm{TiO}_{3}\right)_{(1-\mathrm{x})}-\left(\mathrm{BaTiO}_{3}\right)_{\mathrm{x}}$ 상전이 거동 연구}

\author{
이병완, Haosu Luo², 김정규 ${ }^{1 \dagger}$ \\ ${ }^{1}$ 성균관대학교 화학공학과 \\ 2Shanghai Institute of Ceramics, Chinese Academy of Sciences, Shanghai 200031, China
}

(Received Febrary 19, 2020; Accepted March 17, 2020)

\begin{abstract}
In this study, the phase transition behaviors of lead-free $\left(\mathrm{Na}_{1 / 2} \mathrm{Bi}_{1 / 2} \mathrm{TiO}_{3}\right)_{(1-x)}-\left(\mathrm{BaTiO}_{3}\right)_{x}(\mathrm{NBT}-\mathrm{BT})$ are investigated by using Brillouin spectroscopy. The elastic properties, sound velocity and absorption coefficient of NBT-BT are characterized as a function of temperature along different crystallographic axes. The temperature dependences of the elastic constants of NBT-BT near the morphotropic phase boundary are determined for the first time. The unpoled NBT-BT single crystals exhibits the typical relaxor behaviors, presenting broad acoustic and dielectric anomalies. The application of electric field induced discontinuous changes in the elastic properties at $\sim 110^{\circ} \mathrm{C}$, which indicates field-induced phase transition occurred. The electric field also changes the dielectric constant from more relaxor-like to ferroelectric-like dielectric behavior.
\end{abstract}

Keywords: brillouin spectroscopy, lead-free piezoelectric, relaxor ferroelectrics, phase transition

서론

압전소자 분야에서 가장 많이 쓰이고 있는 소재는
$\mathrm{PbZr}_{1-\mathrm{X}} \mathrm{Ti}_{\mathrm{X}} \mathrm{O}_{3}(\mathrm{PZT})$ 이다. $\mathrm{PZT}$ 는 페로브스카이트 계 강 유전체 물질로 압전계수와 에너지 변환 효율이 높은 특 징을 가지고 있으며, 각종 센서와 전자 소자 등에 활용

†Corresponding Author: Jung Kyu Kim

E-mail: legkim@skku.edu 


\section{특 집 ㅁㅁ 이병완, Haosu Luo, 김정규}

되고 있다 ${ }^{1)}$. 하지만 세계적으로 납이나 수은 같은 중금 속 사용을 규제하고 있어 PZT처럼 납 기반의 소자들의 대체하려는 친환경 소재에 대한 연구가 활발히 이루어 지고 있다 ${ }^{2)}$. 비납계 압전 소자들의 성능은 일반적으로 납기반의 압전 소자보다 열등하지만 이러한 친환경적인 요소로 인해 많은 주목받고 있다. 현재 비납계 압전 소 자 중 $\left(\mathrm{Na}_{1 / 2} \mathrm{Bi}_{1 / 2} \mathrm{TiO}_{3}\right)_{(1-\mathrm{x})}-\left(\mathrm{BaTiO}_{3}\right)_{\mathrm{x}}$ 물질이 압전 상수 및 퀴리 온도가 비교적 높은 것으로 보고되고 있다 ${ }^{3-5)}$. 우수한 질의 NBT-BT 단결정이 성공적으로 성장된 이 후로 비납계 압전소자에 대한 연구가 활발히 진행되고 있다.

$\mathrm{NBT}-\mathrm{BT}$ 는 $\mathrm{Pb}\left(\mathrm{Mg}_{1 / 3} \mathrm{Nb}_{2 / 3}\right) \mathrm{O}_{3}(\mathrm{PMN})$ 이나 $\mathrm{Pb}$ $\left(\mathrm{Mg}_{1 / 3} \mathrm{Nb}_{2 / 3}\right) \mathrm{O}_{3}-\mathrm{PbTiO}_{3}(\mathrm{PMN}-\mathrm{PT})$ 같은 완화형 강유 전체(relaxor ferroelectrics)로 분류되고 있다. 완화 형 강유전체는 독특한 구조적 특성과 함께 이로 인해 조성 무질서도(compositional disorder)를 갖는 결정 이다 ${ }^{6)}$. 완화형 강유전체에 대해서는 아직도 많은 연구 가 필요하지만, 고온에서는 극성의 띄지 않는 상유전성 (Paraelectric)상태로 존재하고, 이는 보통 강유전체의 상유전성과 비슷하다. 그렇지만 냉각 시 방향성을 가지 는 쌍극자 모멘트가 무작위로 배열되어 작은 범위로 극 성을 띄는 국소 분극 구역(Polar nanoregions, PNRs) 를 생성하게 된다. 번즈 온도(Burns Temperature)에 서 발행하는 PNRs에 의한 변화는 거시적으로는 결정 의 대칭성 변화를 만들지 않기 때문에 구조적 상전이 로 간주될 수 없다 ${ }^{7}$. 하지만 PNRs는 결정체의 동적 거 동에 영향을 미치므로 독특한 물리적 성질을 나타낸다. $\mathrm{NBT}-\mathrm{BT}$ 는 $\mathrm{BaTiO}_{3}$ (BT)의 조성별로 다른 상전이 특 성을 보인다. 상평형도에 따라 고온에서는 모두 입방정 계(cubic)의 상유전상이지만 $\mathrm{BaTiO}_{3}$ 의 함유가 0-6\%인 곳에서는 온도에 따라 상유전체에서 반강유전체(Antiferroelectric)로, 반강유전체에서 강유전체 마름모계 (Ferroelectric Rhombohedral)상으로 상전이하게 된 다는 보고가 있다 ${ }^{3)} . \mathrm{BaTiO}_{3}$ 의 함유가 7-17\%인 곳에서 는 상유전상에서 반강유전상으로, 반강유전상에서 강유 전체 정방 정계상(Tetragonal phase)으로 상전이 하게 된다. $\mathrm{BT}$ 의 조성이 $17 \%$ 이상인 곳에서는 상유전상에서
강유전상 정방 정계상(Tetragonal phase)으로 상전이 한다. BT의 조성이 6 8\% 정도인 소위 morphotropic phase boundary (MPB) 근처에서는 압전성, 유전상 수 및 전기기계결합계수 등이 높아진다고 알려져 있다. $\mathrm{MPB}$ 조성의 NBT-BT가 압전 소자의 성능 면에서 매우 중요함에 따라 본 연구에서는 해당 조성의 NBT-BT 단 결정에 대해 레이저 광산란 분광법인 브릴루앙 분광법 을 이용해 상전이 특성을 조사하였다.

\section{본론}

\section{강유전 상전이와 완화형 강유전체}

고체의 전기적 특성에 따르면 전기전도도에 따라 크 게 도체, 부도체, 반도체로 나눌 수 있으며, 부도체 중에 는 유전체도 포함된다. 유전체는 전기적으로 중성이지 만 전기분극(Electric Polarization)을 가지고 있어 부도 체와 비교된다. 특히, 강유전체는 외부 전기장이 없어도 스스로 자발분극(Spontaneous polarization)을 형성함 과 동시에 외부의 전기장에 따라 분극의 방향이 변하는 물질군을 일컫는다. 강유전체는 압전성과 초전성을 모 두 가지고 있고 상대적으로 우수한 특성을 띤다. 따라서 강유전체를 이용하여 압전성과 초전성을 연구함과 동시 에 압전 소자, 초전 소자도 개발할 수 있다.

완화형 강유전체 유전율 측정 시 온도 변화에 따라 유 전율이 완만히 변하고, 주파수에 따라서 유전상수가 최 대가 되는 온도인 $T_{m}$ 에서 유전율이 넓고, 주파수에 따라 서 $T_{m}$ 의 위치가 변하는 것으로 알려져 있고, 이로 인해 유전상수가 매우 날카롭게 변하는 일반 강유전체와 구 별할 수 있다. ${ }^{8)}$

완화형 강유전체 두가지 유형이 있다. 첫 번째 유형 은 그림1(b)와 같이 $T_{\mathrm{C}}$ 에서 long-range ferroelectric order을 발생시키는 것이고, 두 번째 유형은 그림 1(c) 와 같이 거시적인 상전이를 나타내지 않는 고전적인 강 유전체이다. 완화형 강유전체에서는 $\mathrm{B}$-사이트를 점유 하는 두 종류의 양이온이 $1: 1$ 로 정렬된 화학적 질서 영 역(chemically ordered regions, COR)이 존재한다. $\mathrm{COR}$ 은 정적이고 안정적이며 온도와 무관한 것으로 알 

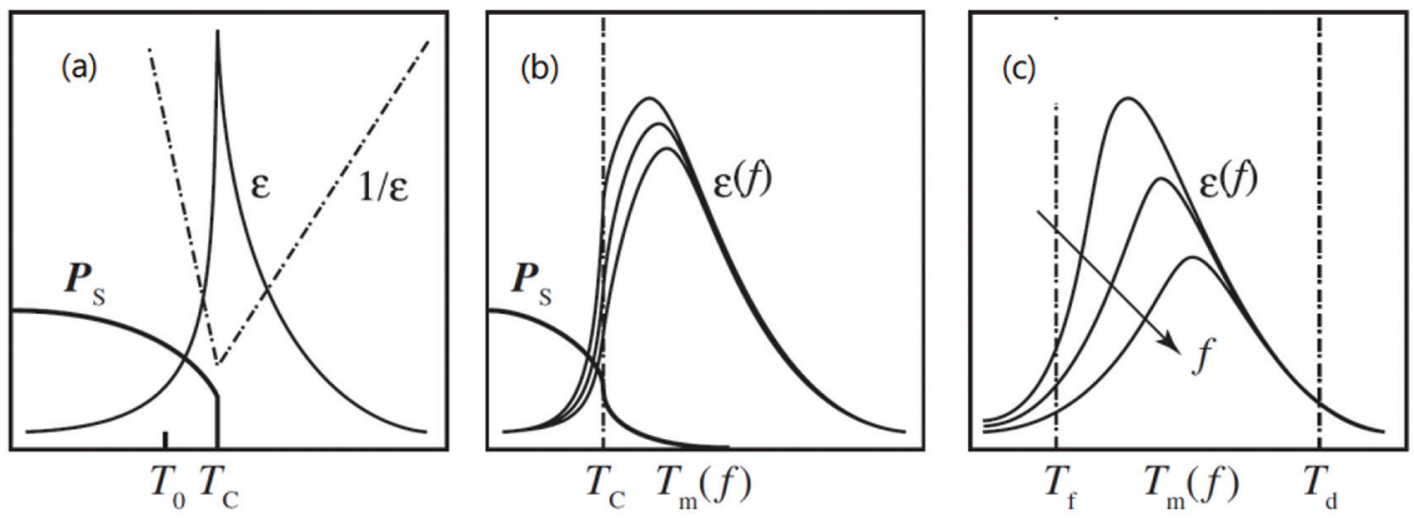

그림 1. (a)정상적인 강유전체, (b)상전이 특성이 있는 완화형 강유전체 (c)고전적인 릴랙서의 유전율 및 특성 온도들 $\left(T_{B} T_{m}, T_{c}\right)$ 의 거동)

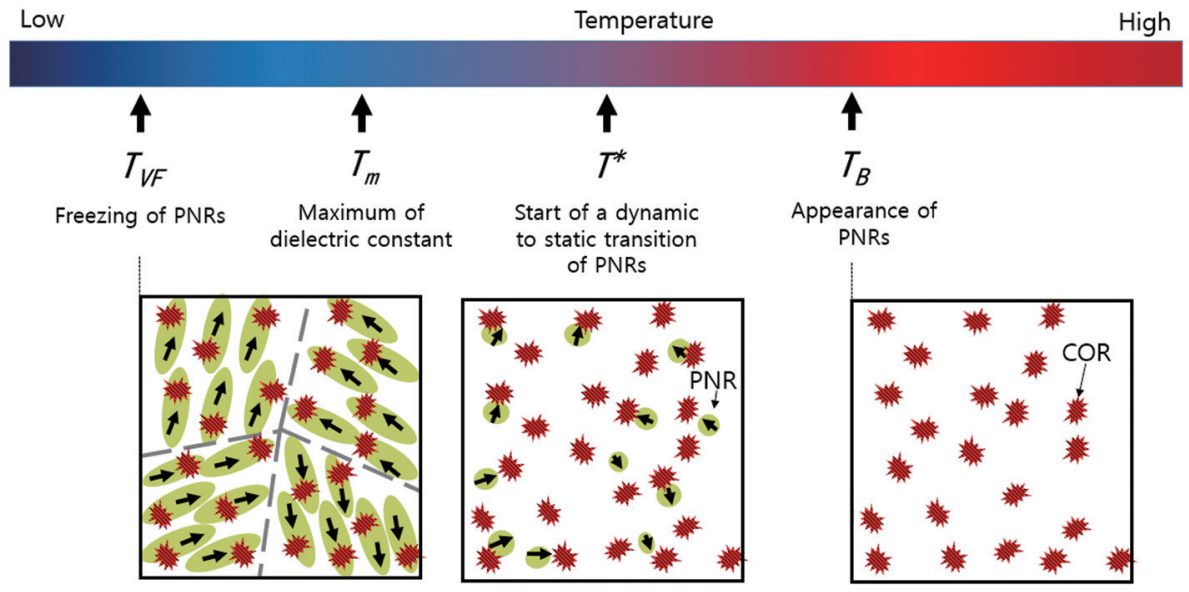

그림 2. 릴랙서 내 PNRs 및 CORs의 온도 의존성

려져 있다. 완화형 강유전체의 또 다른 특징은 나노스케 일의 국부적인 분극이 존재하고 그 방향이 열적 요동 의 해 무작위로 뒤집히는 PNRs의 존재이다. 온도 변화에 따른 PNRs의 구조적, 동적 특성의 변화로부터 몇 가지 특성 온도를 정의하고 논의할 수 있다. 고온부터 냉각 할 때, 굴절률이 고온의 선형성에서 벗어나는 번즈 온도 인 $T_{B}$ 이 있고, 이는 일반적으로 유전상수가 최대치가 되 는 $T_{m}$ 나 큐리온도인 $\mathrm{Tc}$ 보다 더 높은 온도에 존재한다 ${ }^{7)}$. $\mathrm{PNRS}$ 는 $T_{B}$ 에서 형성되기 시작하고, 이 상태를 ergodic relaxor state상태라 부른다. 온도를 더 낮추면 $T^{*}$ 에 서는 $\mathrm{PNRS}$ 의 크기가 커지며 동적 거동이 현저히 느려 지기 시작한다 ${ }^{9)}$. 즉 준정적(quasi-static) 상태로 변하 는 것이다. $T_{m}$ 에서는 유전율이 최대치가 된다. 유전상
수의 분석에 따른 완화시간(relaxation time)이 발산하 는 Vogel-Fulcher 온도인 $T_{V F}$ 에서는 PNRs의 움직임 이 완전히 멈추는 동적 동결(freezing) 상태가 된다. 그 림 2 에서는 완화형 강유전체 온도 의존성에 따른 동적 거동의 상태 변화를 특성 온도들과 함께 나타낸 그림이 다. ${ }^{10,11)}$

\section{브릴루앙 산란 실험}

압전체의 상전이 거동을 확인하기 위해서 비탄성 광 산란 실험인 브릴루앙 산란 실험을 진행하였다. 비탄성 광산란 실험은 결정 안으로 입사된 빛(광자)의 에너지 가 열적으로 여기된 원자들에 의한 격자진동에 해당하 는 에너지만큼 변화하는 과정을 측정한다. 브릴루앙 광 


\section{특 집 ㅁㅁ이영완, Haosu Luo, 김정규}

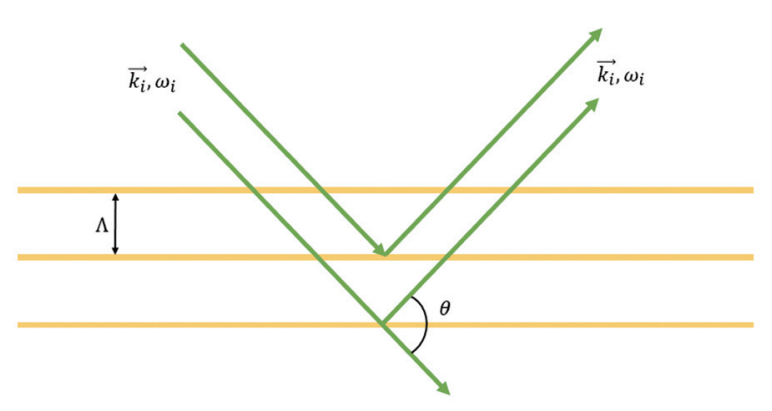

그림 3. 결정에서의 광산란 모식도

산란 분광법은 첫 번째 브릴루앙 영역(first Brillouin zone) 가운데 부근에서 입사광자와 음향포논의 상호작 용에 의해 발생하는 광산란 신호를 측정한다. 각진동수 가 $\omega_{i}$ 인 광자가 파수벡터 $\vec{k}_{i}$ 로 결정 안으로 진행하면 브 릴루앙 산란에 의해 광자의 각진동수와 파수벡터는 $\omega_{s}$, $\vec{k}_{s}$ 으로 산란되어 나온다.

브래그 산란(Bragg scattering) 및 음파의 진행에 의 한 도플러 효과에 따르면 파수벡터 사이의 관계는 다음 과 같이 정리 된다 ${ }^{13)}$.

$$
\begin{gathered}
k_{s}-k_{i}= \pm q \\
q=\frac{2 \pi}{\Lambda}=\frac{4 \pi n}{\lambda} \sin \frac{\theta}{2} \\
2 n \Lambda \sin \frac{\theta}{2}=\lambda
\end{gathered}
$$

여기서 $\vec{q}$ 는 음향포논의 산란 벡터이고, $n$ 은 결정의 굴
절률, $\Lambda$ 는 최대 혹은 최소 밀도간의 거리 또는 음향포논 의 파장, $\theta$ 는 입사된 빛과 산란된 빛 사이의 산란 각도이 다. (식 1)에서 $+\vec{q}$ 는 빛이 격자진동에 해당하는 에너지 를 흡수하는 Anit-Stokes 산란에 해당하고 $-\vec{q}$ 는 에너 지를 빼앗기는 Stokes산란에 해당한다. 포논의 진동수 는 다음과 같은 식으로 나타낼 수 있다.

$$
v=\frac{V}{\Lambda}
$$

(식 4)에 (식 3)를 대입하면 다음과 같은 식이 된다.

$$
v=\frac{2 n V}{\lambda} \sin \frac{\theta}{2}=\frac{q V}{2 \pi}
$$

따라서 음속도 $V$ 는 다음과 같은 식으로 나타내진다.

$$
V=\frac{2 \pi v}{q}
$$

음속도 $V$ 를 이용하여 샘플 내부에서 물질의 거동을 분석 할 수 있다.

역산란 구도 실험에서는 축 방향 별로 나누어 정리 하였다. 서로 다른 결정 축 방향에 대해 브릴루앙 역산 란 실험을 진행하였으며, [100]축 방향에서는 그림 4 의 (a)와 같은 스펙트럼을 얻었다. 약 $50 \mathrm{GHz}$ 근방에서 종음향 모드(longitudinal acoustic mode(LA mode)) 의 Brillouin frequency가 측정된다. 역산란 구도에서 는 입방정계의 $\langle 100\rangle$ 방향으로 진행하는 횡음향모드 (transverse acoustic mode (TA mode))는 측정되지 않는다.

그림 4의 (b)에서 $0 \mathrm{GHz}$ 을 중심으로 한 중앙피크
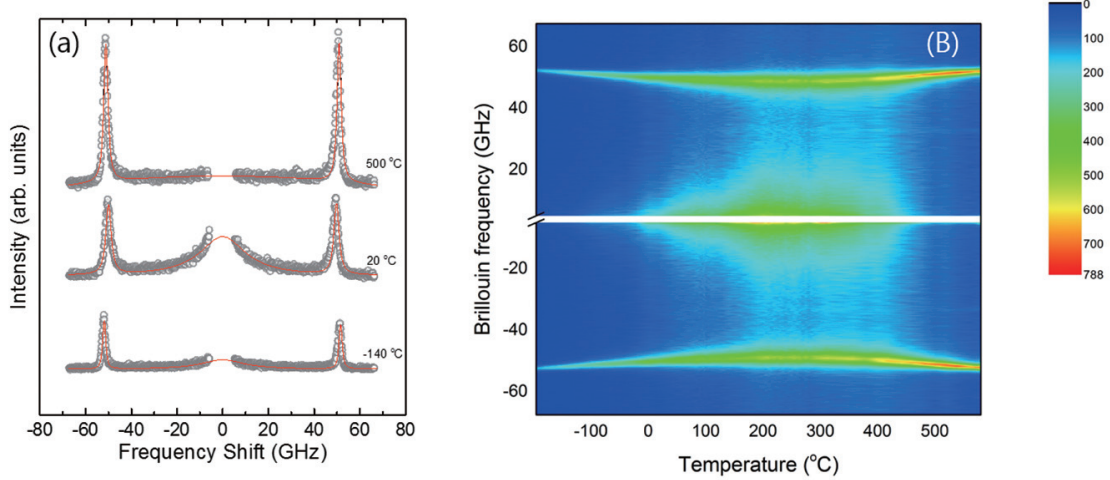

그림 4. NBT-BT[100]의 (a)브릴루앙 스펙트럼 (b) 온도의존성 그래프 
납이 포함되지 않은 압전 특성의 $\left(\mathrm{Na}_{1 / 2} \mathrm{Bi}_{1 / 2} \mathrm{TiO}_{3}\right)_{(1-x)}-\left(\mathrm{BaTiO}_{3}\right)_{x}$ 상전이 거동 연구

(Central Peak)가 $0^{\circ} \mathrm{C}$ 이하에서 약하게 존재하고, 약 0 ${ }^{\circ} \mathrm{C}$ 부터 $400^{\circ} \mathrm{C}$ 까지의 온도구간에서는 중앙피크가 강하 게 나타남을 알 수 있다. $400^{\circ} \mathrm{C}$ 이상에서는 중앙피크 가 점점 사라지는 것으로 확인되었다. 그림 4 (a)에서는 LA mode의 Brillouin shift의 온도의존성을 보여주는 데, 브릴루앙 주파수가 넓은 영역에 걸쳐 완만하게 변하 는 것을 보여준다.

그림 5의(b)의 반치폭 (Full width half maximum, $\mathrm{FWHM}$ ) 역시 뚜렷한 상전이 구간을 구별할 수 없고 넓
은 온도에 걸쳐 완만하게 바뀐다. 이는 완화형 강유전체 의 대표적인 특징이다. cooling할 때와 heating할 때의 온도에 따른 Brillouin shift의 차이는 거의 없었다.

그림 $6 \mathrm{NBT}-\mathrm{BT}$ 의 역산란 Brillouin shift 및 FWHM 의 온도의존성 데이터 $(\mathrm{a})(\mathrm{b})$ 축 방향 [110], (c)(d)축 방 향 [111]

그림 6은 0.95NBT-0.5BT의 [110]와 [111] 방향으 로 진행하는 음향포논의 브릴루앙 주파수와 반치폭의 온도의존성을 보여준다. 그림 6 (a)는 축방향 [110]으

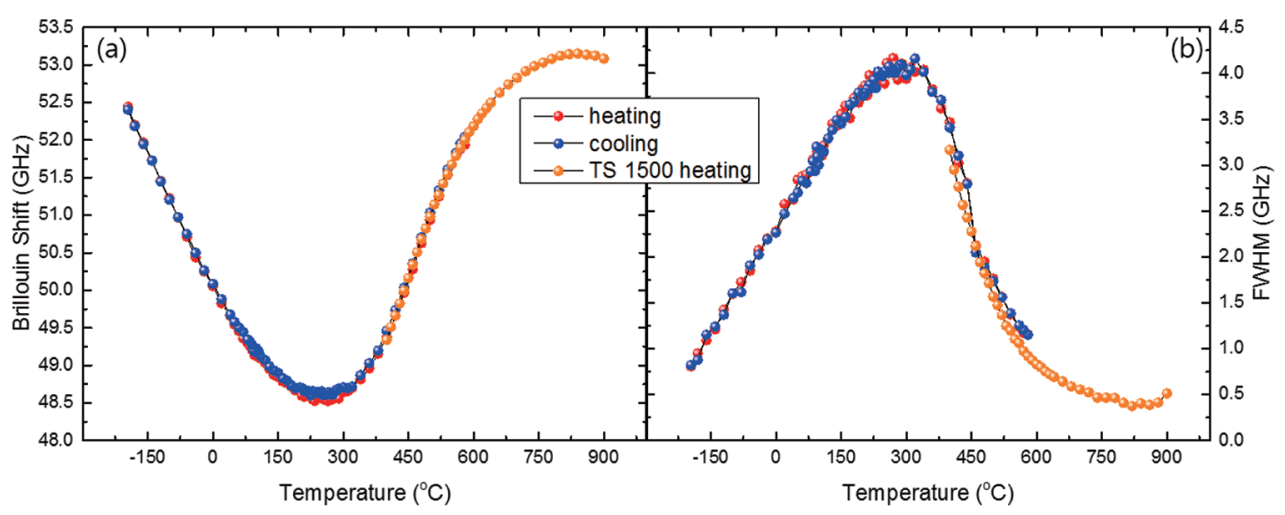

그림 5. NBT-BT[100]의 역산란 구도에서의 브릴루앙 온도의존성 데이터
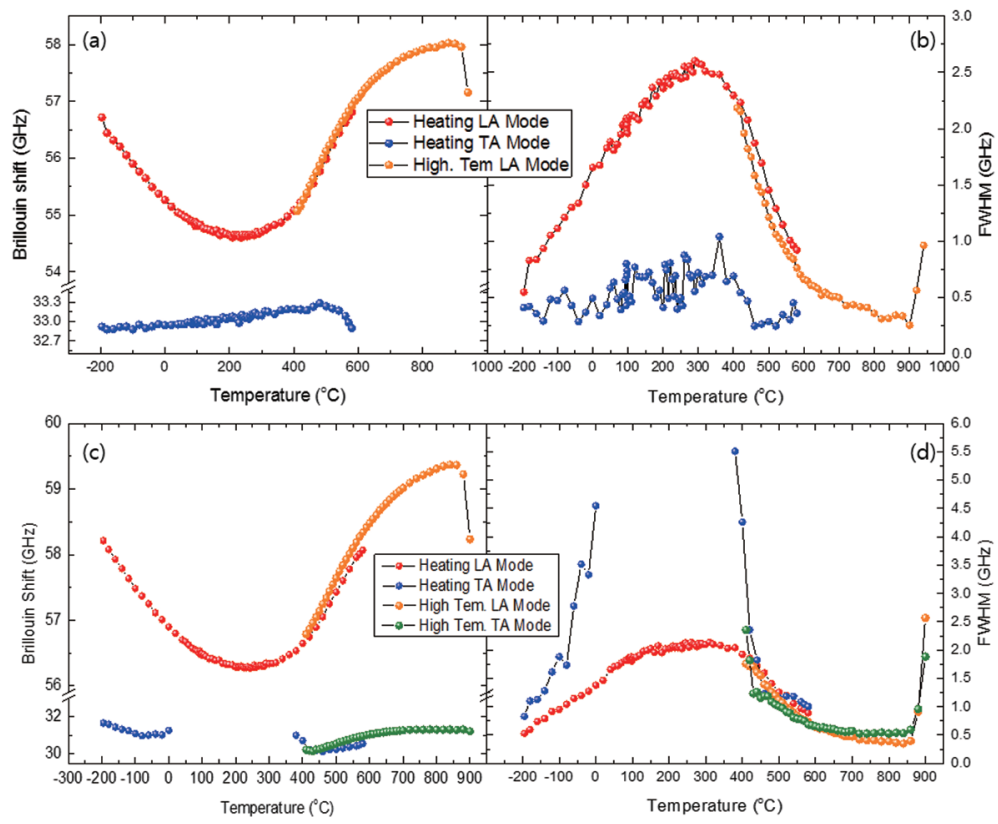

그림 6. NBT-BT의 역산란 Brillouin shift 및 FWHM의 온도의존성 데이터 (a)(b)축 방향 [110], (c)(d)축 방향 [111] 

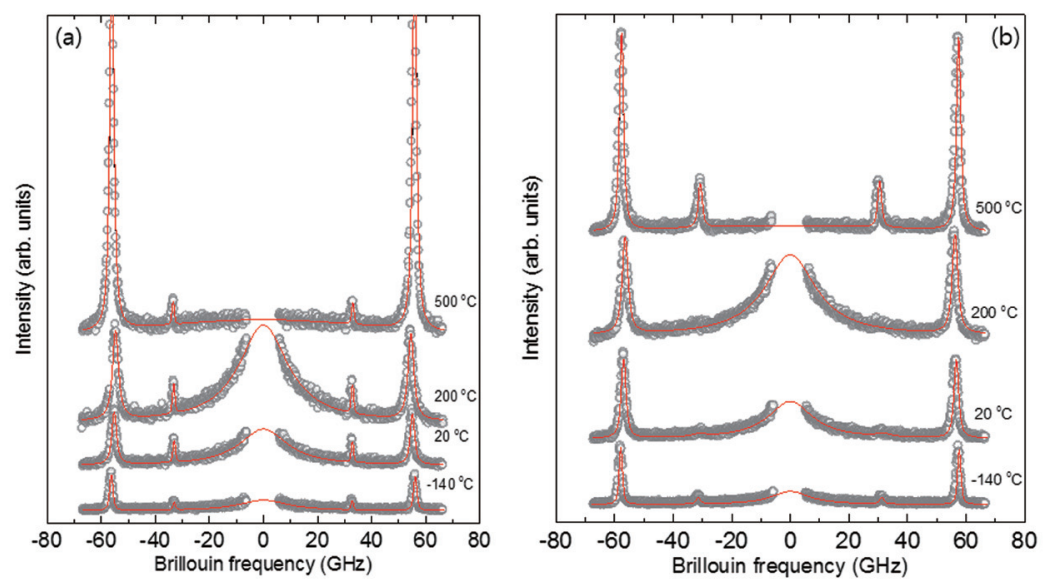

그림 7. NBT-BT의 브릴루앙 스펙트럼 (a)[110] (b)[111]

로 진행하는 LA mode에 대해 $-196^{\circ} \mathrm{C}$ 부터 $900^{\circ} \mathrm{C}$ 까 지 heating 과정에서 얻은 데이터이다. [100] 방향에서 보이지 않았던 TA mode가 측정되며, $600^{\circ} \mathrm{C}$ 부터는 $\mathrm{TA}$ mode가 측정되지 않는다.

그림 7(a)는 [110] 방향으로 진행하는 음향포논에 대한 브릴루앙 스펙트럼을 보여준다. $500^{\circ} \mathrm{C}$ 에서 $\mathrm{TA}$ mode가 약해지는 것이 확인되었다. 그림 7(c)은 축 방 향 [111]에 대해서는 $0^{\circ} \mathrm{C}$ 부터 약 $400^{\circ} \mathrm{C}$ 까지 TA mode가 거의 측정되지 않음을 보여준다. 그림 7(b)의 브릴루앙 스펙트럼을 보면 TA mode가 약하게 보이는 것을 알 수 있다. $0^{\circ} \mathrm{C}$ 부터 약 $400^{\circ} \mathrm{C}$ 까지 매우 약한 TA mode가 보 이지만 곡선맞춤(curve fitting)은 불가능하였다. 하지

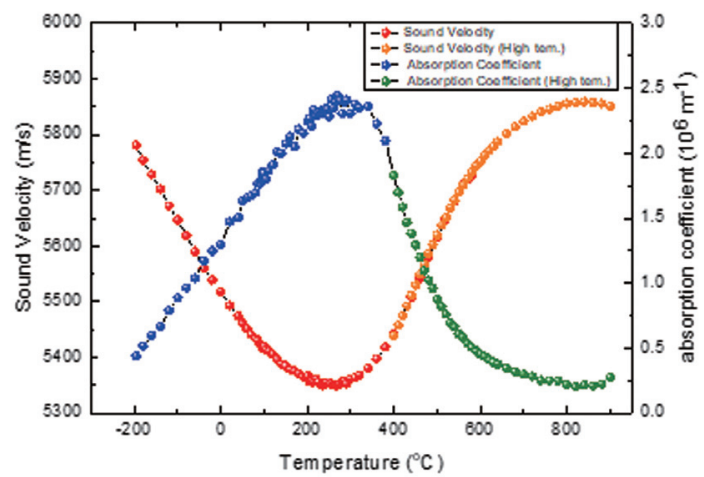

그림 8. NBT-BT[100]의 음속도와 흡수계수의 온도의존성
만 $400^{\circ} \mathrm{C}$ 이상부터는 매우 강하게 측정되며, 반치폭 또 한 정확히 구할 수 있었다.

그림 8에서는 NBT-BT의 [100]축 방향에 대해 얻은 데이터를 기반으로 음속도와 흡수계수가 온도의 함수로 제시되어 있다. 역산란 구도에서 음속도 $V$ 는 식(7)와 다 음과 같은 식으로부터 얻을 수 있다[16,17,18].

$$
2 \pi v_{B}=q V
$$

$$
V=\frac{2 \pi v_{B} \lambda}{4 \pi n}=\frac{v_{B} \lambda}{2 n}
$$

여기서 $v_{B}$ 는 역산란 구도에서 얻은 브릴루앙 산란 주 파수를, $n$ 은 샘플의 굴절률을 의미한다. 여기에서 샘플 의 굴절률은 온도에 따라 변하지 않는다고 가정하였고, 문헌상의 수치인 2.503으로 설정하였다 ${ }^{19)}$. 위의 식에서 볼 수 있듯이 음속도는 브릴루앙 주파수에 선형으로 비 례한다. 흡수계수(Absorption Coefficient, $\alpha$ )는 음향 포논의 에너지 손실과 관련되며 브릴루앙 주파수의 반 치폭과 음속도를 이용해 구한다 ${ }^{16,20)}$.

$$
\alpha=\frac{\pi \Gamma}{V} \text {. }
$$

여기서 $I$ 는 브릴루앙 주파수의 반치폭이고, $V$ 는 음속 도이다. 흡수계수는 반치폭에 비례하고, 음속도에 반비 례 한다.

그림 9은 NBT-BT의 [100] 방향으로 전기장을 인가 
납이 포함되지 않은 압전 특성의 $\left(\mathrm{Na}_{1 / 2} \mathrm{Bi}_{1 / 2} \mathrm{TiO}_{3}\right)_{(1-x)}-\left(\mathrm{BaTiO}_{3}\right)_{x}$ 상전이 거동 연구

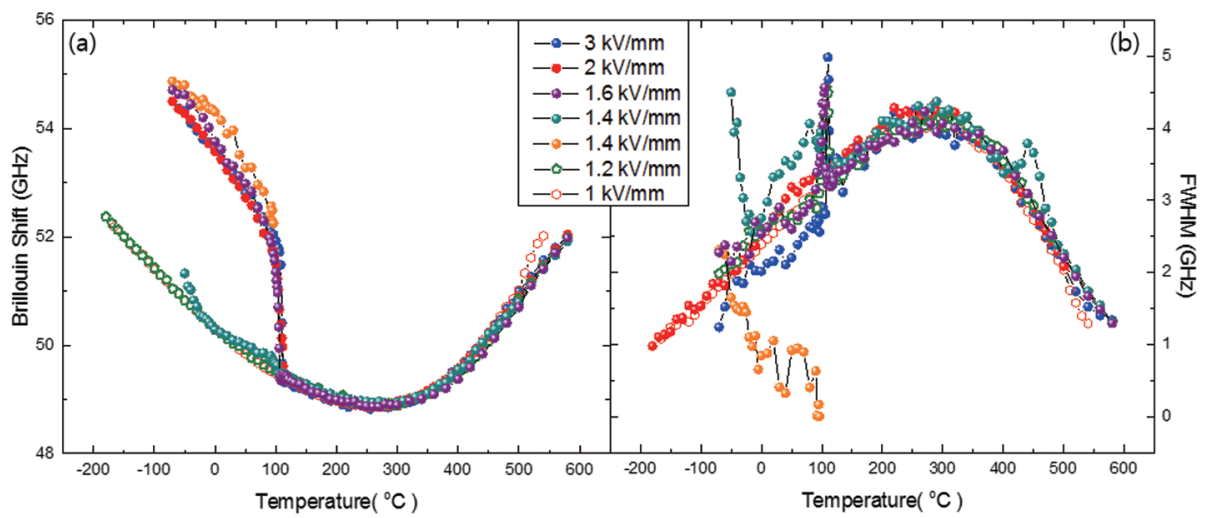

그림 9. 인가 전기장에 따른 NBT-BT[100]의 역산란 구도에서의 (a)브릴루앙 주파수와 (b)반치폭의 온도 의존성

해 폴링한 시료에 대한 브릴루앙 산란 스펙트럼의 온도 의존성을 보여준다. 이 결과를 얻기 위해 전기장을 인가 해 poling한 후 액체질소를 사용하여 영하 $-196^{\circ} \mathrm{C}$ 부터 $600^{\circ} \mathrm{C}$ 까지 온도를 증가시키면서 측정하였다. $1 \mathrm{kV} / \mathrm{mm}$ 와 $1.2 \mathrm{kV} / \mathrm{mm}$ 의 전기장을 인가한 후 측정한 결과는 전 기장을 인가하지 않았을 때와 동일한 결과를 얻었다. 하 지만 $1.4 \mathrm{kV} / \mathrm{mm}$ 이상 전기장을 인가한 결과에서는 전 기장을 인가하지 않았을 때와 확연히 다른 경향성을 보 임을 알 수 있었다. 전기장을 인가하지 않았을 때와 비 교해서 브릴루앙 주파수가 증가하였다. 이후 약 $110^{\circ} \mathrm{C}$ 부 근에서 전기장을 인가하지 않았을 때와 동일한 경향성 을 보였다. 이는 PNRs가 전기장에 반응하여 저온에서 정렬되었다가 온도가 증가하면서 전기장에 의해 속박된 $\mathrm{PNRs}$ 가 서서히 속박이 풀리면서 전기장을 인가하지 않 았을 때로 되돌아감을 의미한다. 특히 $1.4 \mathrm{kV} / \mathrm{mm}$ 에서 는 전기장을 인가했을 때와 인가하지 않았을 때 보이는 LA mode의 피크가 중첩되어 보이는 현상을 확인하였 다. 이 전기장에서는 일부 PNRs는 전기장과 반응한 후 속박되고, 일부 PNRs는 속박되지 않은 것으로 보인다.

그림 10 은 전기장을 $1.4 \mathrm{kV} / \mathrm{mm}$ 조건 하에서 인가한 후 측정한 브릴루앙 스펙트럼을 보여준다. $-50^{\circ} \mathrm{C}$ 에서는 고주파수의 피크(약 $55 \mathrm{GHz}$ 부근)가 강하게 측정되며 저 주파수에서 도출된 피크(약 $52.5 \mathrm{GHz}$ 부근)는 매우 약하 게 측정된다. 온도 상승에 따라서 고주파수 성분의 피크 는 점점 약해지며 저주파수 성분의 피크는 강해졌다. 그

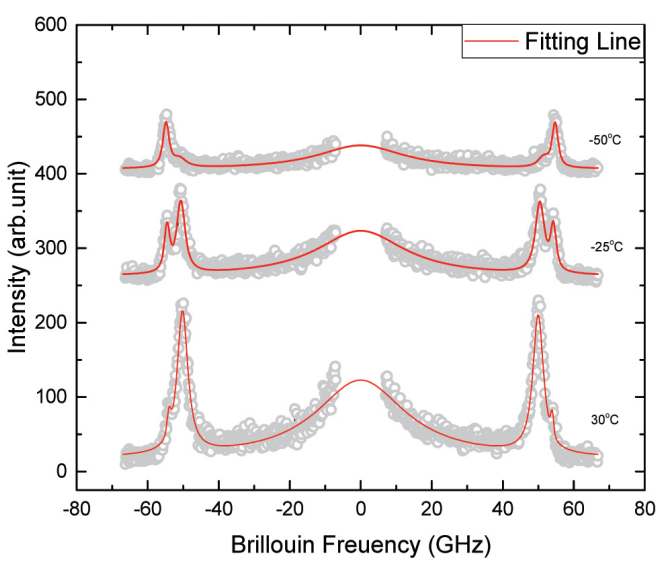

그림 10. 전기장 인가 후 $(1.4 \mathrm{kV} / \mathrm{mm}) \mathrm{NBT}-\mathrm{BT}[100]$ 의 역산란 구도 에서의 브릴루앙 스펙트럼의 온도 의존성 데이터

뒤 $110^{\circ} \mathrm{C}$ 부근에서는 고주파수의 피크는 완전히 사라지 며 전기장을 인가하지 않았을 때와 동일한 경향을 보인 다. 두 피크가 공존하는 온도 범위에서는 강유전성 영역 과 $\mathrm{PNRS}$ 이 존재하는 완화형 강유전체의 영역이 공존하 는 것으로 해석된다.

\section{결론}

본 연구에서는 비납계 압전 물질인 NBT-BT의 상전 이 거동을 비탄성 레이저 광산란 분광법으로 조사하셨 다. poling되지 않은 $\left(\mathrm{Na}_{1 / 2} \mathrm{Bi}_{1 / 2} \mathrm{TiO}_{3}\right)(1-\mathrm{x})-\left(\mathrm{BaTiO}_{3}\right) \mathrm{x}$ 의 탄성특성을 브릴루앙 분광법으로 조사한 결과 음속 
도와 흡수계수가 매우 넓은 온도 범위에서 완만히 변하 는 것을 확인하였다. 이러한 특성은 성장된 NBT-BT 단 결정이 뚜렷한 상전이를 보이지 않는 완화형 강유전체 의 거동을 보여줌을 의미한다.

상온에서 NBT-BT에 전기장을 인가한 후 가열 과정 에서 탄성특성을 조사한 결과, 약 $110^{\circ} \mathrm{C}$ 의 온도에서 브 릴루앙 주파수와 반치폭이 불연속적으로 변함을 확인하 였다. 이는 상온에서 PNRs가 전기장에 반응하여 거시 적 분극으로 정렬되다가 온도가 증가하면서 특정 온도 에서 강유전 분극이 사라지면서 릴랙서의 상태로 되돌 아감을 의미한다고 해석된다. 특히 $1.4 \mathrm{kV} / \mathrm{mm}$ 에서는 종음향 모드의 피크가 두 개로 갈라짐이 확인되었고 이 는 해당 전기장에서 강유전상과 완화형 강유전상의 상 태가 공존한다고 해석된다.

\section{REFERENCES}

1. B. Jaffe, W. R. Cook and H. Jaffe, "Piezoelectric Ceramics”, Academic Press Ltd., London, (1971).

2. Y. Saito, H. Takao, T. Tani, T. Nonoyama, K. Takatori, T. Homma, T. Nagaya and M. Nakamura, "Materials science: Lead-free at last”, Nature 432,84, (2004).

3. Wenwei Ge, Hong Liu, Xiangyong Zhao, Bijun Fang, Xiaobing Li, Feifei Wang, Dan Zhou, Ping Yu, Xiaoming Pan, Di Lin and Haosu Luo "Crystal growth and high piezoelectric performance of $0.95 \mathrm{Na}_{0.5} \mathrm{Bi}_{0.5} \mathrm{TiO}_{3}-0.05 \mathrm{BaTiO}_{3}$ lead-free ferroelectric materials", J. Phys. D: Appl. Phys., 41, 115403, (2008).

4. H. Wang, R. Zuo, X. Ji, Z. Xu, "Effects of ball milling on microstructure and electrical properties of sol-gel derived $\left(\mathrm{Na}_{0.5} \mathrm{Bi}_{0.5}\right)_{0.94} \mathrm{Ba}_{0.06} \mathrm{TiO}_{3}$ piezoelectric ceramics", Mater Des, 31, 4403-7, (2010).

5. A. Ullah, C.W Ahn, A. Hussain,I.W. Kim, "The effects of sintering temperatures on dielectric, ferroelectric and electric fieldinduced strain oflead-free $\mathrm{Bi}_{0.5}\left(\mathrm{Na}_{0.78} \mathrm{~K}_{0.22}\right)_{0.5} \mathrm{TiO}_{3}$ piezoelectric ceramicssynthesized by the sol gel technique”, Curr Appl Phys, 10,1367-71, (2010).
6. L. ERIC CROSS, "RELAXOR FERROELECI" RICS", Ferroebctrirs, Vol. 76, pp. 241-267, (1987).

7. G. Burns and F. H. Dacol, "Crystalline ferroelectrics with glassy polarization behavior", Phys. Rev. B, 28, 2527, (1983).

8. K. Hirota, S. Wakimoto, and D. E. Cox, "Neutron and X-ray Scattering Studies of Relaxors", J. Phys. Soc. Jpn. 75, 111006, (2006).

9. E. Dul'kin, M. Roth, P.-E. Janolin, and B. Dkhil, "Acoustic emission study of phase transitions and polar nanoregions in relaxorbased systems: Application to the $\mathrm{PbZn}_{1 / 3} \mathrm{NB}_{2 / 3} \mathrm{O}_{3}$ family of single crystals", Phys. Rev. B, 73, 012102, (2006).

10. S. Kojima and J. - H. Ko, "Broadband microBrillouin scattering spectroscopy of $\mathrm{Pb}\left(B_{1 / 3} B_{2 / 3}^{\prime}\right)$ $\mathrm{O}_{3}$-based relaxor ferroelectrics", Curr. Appl. Phys., 11 S22, (2011).

11. D. Fu, H. Taniguchi, M. Itoh, S. - Y, Koshihara, N. Yamamoto, and S. Mori, "Relaxor $\mathrm{Pb}\left(\mathrm{Mg}_{1 / 3} \mathrm{Nb}_{2 / 3}\right) \mathrm{O}_{3}:$ A Ferroelectric with Multiple Inhomogeneities", Phys. Rev. Lett., 103, 207601, (2009).

12. A. A. Bokov, Z. -G. Ye, "Recent progress in relaxor ferroelectrics with perovskite structure" Journal of Materials Science, 41, 31-52, (2006).

13. S. Speziale, H. Marquardt, T. S. Duffy, "Brillouin Scattering and its Application in Geosciences", Reviews in Mineralogy and Geochemistry, Vol.78, pp 543-603, (2014).

14. Eugene Hecht, "Optics 4th", Addison-Wesley, (2001).

15. S. Hoffmann-Eifert, D. Richter, S.T. Kinstry, "Dielctric, Ferroelectric, and Optical Properties". NE3rd 12.book Seite 33 Dienstag, 14. Februar (2012).

16. J. Petzelt, G. V. Kozlov, A.A. Volkov, "DIELECTRIC SPECTROSCOPY OF PARAELECTRIC SOFT MODES", Ferroebctrirs, Vol. 73, pp. 101-123, (1987).

17. A. Peláiz-Barranco and J. D. S. Guerra, "Dielectric Relaxation Phenomenon in Ferroelectric Perovskite-related Structures". Ferroelectrics, (2010) 
납이 포함되지 않은 압전 특성의 $\left(\mathrm{Na}_{1 / 2} \mathrm{Bi}_{1 / 2} \mathrm{TiO}_{3}\right)_{(1-x)}-\left(\mathrm{BaTiO}_{3}\right)_{x}$ 상전이 거동 연구

18. J.-H. Ko, M.-S. Jeong B. W. Lee, J. H. Kim, Y. H. Ko, K. J. Kim, T, H, Kim, S. Kojima, and $\mathrm{M}$ Ahart, "Pressure Dependence of Acoustic Properties of Liquid Ethanol by using. High-pressure Brillouin Spectroscopy", Korean Journal of Optics and Photonics, Volume 24, Number 5, October, (2013).

19. C. He, X. Yi, T. Wu, J. Wang, K. Zhu, Y. Liu, "Wavelength dependence of refractive index
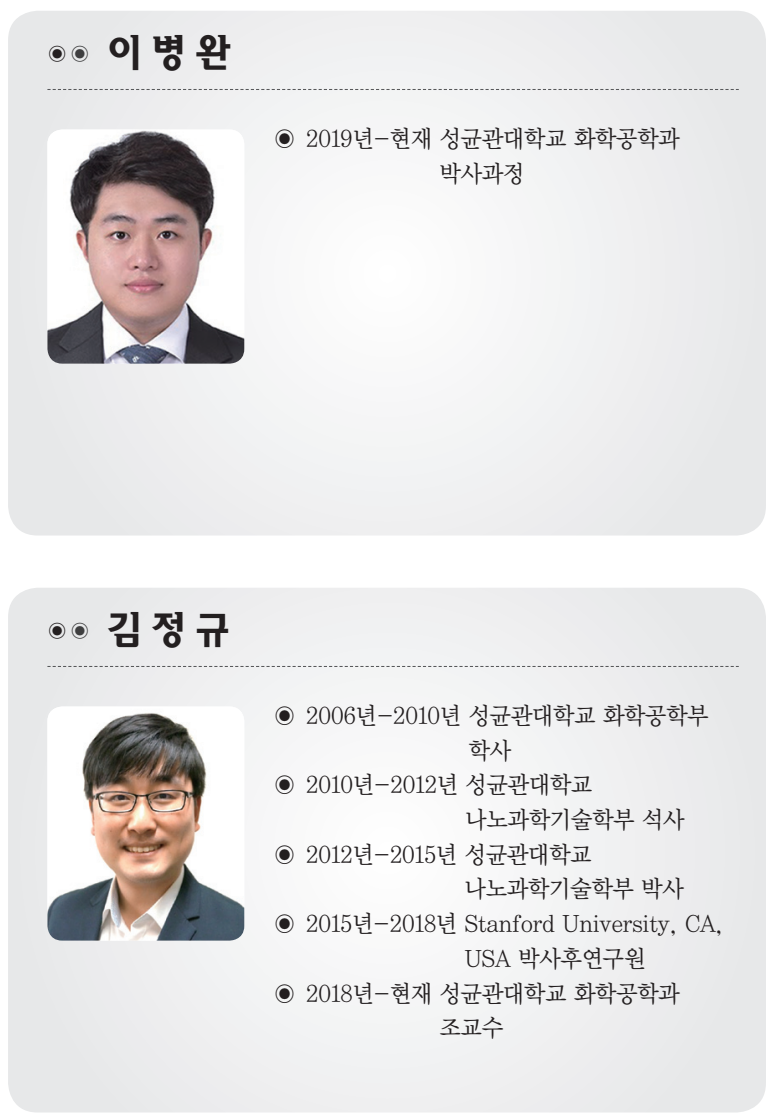

in lead-free $\mathrm{Na}_{0,5} \mathrm{Bi}_{0,5} \mathrm{TiO}_{3}-\mathrm{BaTiO}_{3}$ single crystals", Optical Materials 36, 2023-2025, (2014).

20. J.-H. Ko, T. H. Kim, K. Roleder, D. Rytz, and S. Kojima, "Precursor dynamics in the ferroelectric phase transition of barium titanate single crystals studied by Brillouin light scattering”, Phys. Rev. B Vol. 84, Iss. 9, (2011).

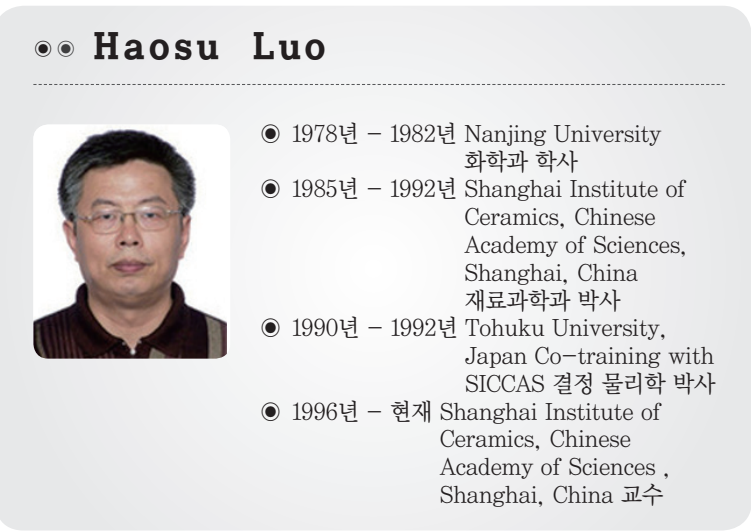

